\title{
A Construção do Direito à Saúde no Brasil
}

\author{
CONSTRUCTING THE RIGHT TO HEALTH IN BRAZIL
}

Sueli Gandolfi Dallari(*)

\section{RESUMO}

O direito à saúde recebeu — pela primeira vez — tratamento constitucional no Brasil em 1988, fruto de grande participação popular. Neste estudo, se busca compreender a extensão dessa afirmação e verificar sua implementação normativa e jurisprudencial. A partir do estudo da evolução dos conceitos de saúde e de direito, concluiu-se que o direito à saúde deve implicar a constante participação popular para que possa ser delimitado. Verificou-se, também, que o arcabouço normativo vem sendo construído em conformidade com as exigências constitucionais. Quanto à construção jurisprudencial, se percebeu que ela vem acontecendo de forma errática e que os tribunais superiores raramente enfrentam a discussão da política de saúde desenhada na Constituição da República Federativa do Brasil de 1988. Concluiu-se que a afirmação constitucional tem demonstrado vigor, haja vista o grande desenvolvimento normativo conforme à compreensão contemporânea; e que o controle judicial da realização da política sanitária é ainda incipiente.

\section{Palavras-chave}

Controle Constitucional de Políticas Públicas; Direito à Saúde; Participação Popular.

\section{ABSTRACT}

The right to health has received - for the first time - constitutional treatment in Brazil in 1988, as a result of great popular participation. This

(*) Coordenadora Científica, Núcleo de Pesquisas em Direito Sanitário da Universidade de São Paulo; Livre-Docente em Direito Sanitário, Universidade de São Paulo; Professora Titular, Faculdade de Saúde Pública da Universidade de São Paulo. E-mail: <sdallari@usp.br>. 
study seeks to understand the scope of this statement and to verify its legal and jurisprudential implementation. From the study of the evolution of health and law concepts it concludes that the right to health must involve popular participation in order to be delineated. It also verifies that the regulatory framework is being built in accordance with the constitutional requirements. However, this work realizes that the judicial construction has been happening erratically and that the higher courts rarely face the discussion of the health policy designed in the Brazilian Constitution of 1988. The conclusion is that the statement of the right to health has demonstrated constitutional force, seeing the major legislative development in total coherence to its contemporary understanding and that the judicial control of the implementation of health policy is still nascent.

\section{Keywords} Health.

Popular Participation; Public Policies Constitucional Control; Right to

1. O direito à saúde não foi tema das constituições brasileiras anteriores a 1988, a não ser acidentalmente. Com efeito, em toda a história constitucional apenas o texto da Constituição da República dos Estados Unidos do Brasil, promulgada em 16 de julho de 1934, sugere sua possibilidade ao conferir competência concorrente à União e aos estados para cuidar da saúde (art. 10, II). Ele assinalava, especialmente, às três esferas de governo a incumbência de "adotar medidas legislativas e administrativas tendentes a restringir a mortalidade e a morbidade infantis; e de higiene social que impeçam a propagação das doenças transmissíveis"; e de "cuidar da higiene mental e incentivar a luta contra os venenos sociais" (art. 138, $f$ e $g$ ). Essa mesma Constituição, de efêmera duração(1), tratando da ordem econômica e social incluía entre os preceitos a serem observados pela legislação trabaIhista a assistência médica e sanitária (art. 121, h). Os demais textos constitucionais se limitaram a atribuir competência à União para planejar sistemas nacionais de saúde, conferindo-lhe a exclusividade da legislação sobre normas gerais de proteção e defesa da saúde e mantiveram a necessidade de obediência ao princípio que garantia aos trabalhadores assistência médica e sanitária.

A introdução da saúde no rol dos direitos sociais no Brasil foi, sobretudo, resultado da força dos movimentos populares no momento da redemocratização política, no final dos anos oitenta do século vinte. Nesse rico período da história política brasileira, houve o fenômeno, até então inédito, da expressiva participação popular na definição dos grandes objetivos constitucio-

(1) Foi oficialmente substituída pelo texto de 1937. 
nais ${ }^{(2)}$. Assim, especialmente os profissionais de saúde que haviam feito a opção de ingressar no serviço público para atender às pessoas mais desfavorecidas, em um grande congresso científico de saúde pública(3), começaram a fixar as bases de uma nova política de saúde. Essa nova política já havia sido mencionada no painel Saúde na Constituição, durante a VIII Conferência Nacional de Saúde ${ }^{(4)}$, e deu origem a uma proposta de emenda popular apresentada à Assembléia Constituinte. Também o setor privado com interesse na área da saúde participou ativamente dos debates na Assembléia Constituinte, que terminou por definir a estrutura constitucional da política de saúde pública no país(5) É importante notar que o texto da seção da saúde ${ }^{(6)}$ aprovado é com pequenas modificações - aquele elaborado pelos sanitaristas e apresentado igualmente como emenda popular à Constituição.

A simples afirmação da saúde como um dos direitos sociais constantes do art. 6 da Carta de 1988 poderia, entretanto, guardar o caráter de norma de eficácia contida(7), experiência tradicional do direito constitucional brasileiro, como parece continua tendo a afirmação do direito ao lazer, contida no mesmo art. 6‥ O forte envolvimento popular e, particularmente, a proposta técnica de um sistema de saúde elaborada pelos sanitaristas, pode explicar porque, contrariando a tradição, desde a promulgação da Constituição, o direito à saúde vem sendo eficaz. Com efeito, diferentemente dos demais direitos sociais ali afirmados, apenas o direito à saúde tem sua garantia claramente vinculada às políticas sociais e econômicas, as diretrizes do sistema expressamente formuladas, envolvendo a participação da comunidade, e suas atribuições enumeradas no próprio texto constitucional (CF, arts. 196, 198 e 200).

2. Sendo, portanto, uma inovação constitucional, deve-se procurar compreender o significado da afirmação do direito à saúde realizada em 1988. Para isso, é preciso desvendar os vários sentidos da palavra saúde ${ }^{(8)}$, que

(2) Foram recolhidas cerca de 12 milhões de assinaturas pelo Movimento Pró-Participação Popular na Constituinte, nas 122 propostas apresentadas (Cf. WHITACKER, F. et al. Cidadão constituinte: a saga das emendas populares. Rio de Janeiro: Paz e Terra, 1989. p. 38).

(3) Trata-se do I Congresso Brasileiro de Saúde Coletiva, realizado na cidade do Rio de Janeiro, em setembro de 1986, pela Associação Brasileira de Pós-Graduação em Saúde Coletiva (ABRASCO).

(4) Realizada em Brasília, em abril de 1986, por convocação do então Presidente da República, José Sarney.

(5) Um amplo relatório desse período histórico pode ser encontrado em: RODRIGUES NETO, E. A via do parlamento In: FLEURY, S. (Orgs.) Saúde e democracia: a luta do CEBES. São Paulo: Lemos, 1997. p. 63-91.

(6) Seção II, do capítulo da seguridade social, do Título VIII — Da ordem social.

(7) Dizia o professor José Afonso da Silva na primeira edição de Aplicabilidade das normas constitucionais que as normas programáticas, por terem sua eficácia contida, não caracterizariam um autêntico direito atual. Entretanto, na terceira edição desse clássico estudo, esclarece o referido professor que "o fato de (as normas programáticas) dependerem de providências institucionais não quer dizer que não tenham eficácia. Ao contrário, sua imperatividade direta é reconhecida como imposição constitucional aos órgãos públicos" (Cf. SILVA, J. A. Aplicabilidade das normas constitucionais. 3. ed. São Paulo: Revista dos Tribunais, 1998. p. 155).

(8) Ver DALLARI, S. G. O direito à saúde. Revista de Saúde Pública, São Paulo, v. 22, n. 1, p. 57-63, 1988. 
envolve tanto a percepção de sua dependência das condições de vida e organização social como a noção de ausência de doenças. Tal amplitude foi aceita pela sociedade que sobreviveu a Segunda Grande Guerra do século vinte e ficou clara na criação da Organização Mundial de Saúde (OMS) que, no preâmbulo de sua Constituição (1946), assim conceitua: "Saúde é o estado de completo bem-estar físico, mental e social e não apenas a ausência de doença". A saúde depende, então, ao mesmo tempo, de características individuais, físicas e psicológicas, mas, também, do ambiente social e econômico, tanto daquele mais próximo das pessoas, quanto daquele que condiciona a vida dos Estados.

Ninguém pode, portanto, ser individualmente responsável por sua saúde. Com efeito, o aparecimento de doenças pode estar ligado mais diretamente a características e fatores individuais, embora não deixe de apresentar traços que o liguem à organização social ou política. A maior força dos fatores e características ambientais, econômicas e sociopolíticas fica evidente nas doenças transmissíveis, onde existe uma ameaça à saúde de toda a população e as pessoas individualmente pouco podem fazer para se protegerem, pois ainda que suas condições físicas e psicológicas possam tornar mais fácil ou dificultar seu adoecimento é fácil perceber a predominância da organização social, nacional e global, produzindo doenças. Na realidade, existe um continuum na noção de saúde, que tem em um de seus pólos as características mais próximas do indivíduo e, no outro, aquelas mais diretamente dependentes da organização sociopolítica e econômica dos Estados.

O caso dos medicamentos pode ser um bom exemplo da força de variáveis ligadas à organização da sociedade internacional condicionando diretamente o estado de saúde das pessoas. De fato, os medicamentos além de serem, muitas vezes, uma invenção são também um insumo terapêutico de primeira necessidade para o cuidado da saúde da população. A concessão de uma patente farmacêutica suscita, portanto, preocupações quanto ao abuso do direito de seus titulares e suas implicações para o resguardo da saúde pública e do acesso a medicamentos por parte da população. O acordo TRIPS ${ }^{(9)}$ prevê o direito dos Estados signatários de instituírem, no âmbito de seus ordenamentos jurídicos, leis e regulamentos próprios que objetivem a proteção da saúde e nutrição públicas (art. 8으, inciso I), tanto quanto leis e regulamentos que visem evitar o abuso dos direitos de propriedade intelectual por parte de seus titulares, ou para evitar práticas que restrinjam o comércio ou que afetem de forma adversa a transferência internacional de tecnologia (art. 8ㅜㅡ, inciso II). A implicação disso no estado de saúde das pessoas é evidente, pois o acesso ao medicamento será inviabilizado para quem viva num Estado que não possui o desenvolvimento socioeconômico suficiente para lhe permitir o desenvolvimento de determinado medicamento,

(9) Em português, Acordo ADIP — Acordo da OMC sobre Aspectos dos Direitos de Propriedade Intelectual Relacionados ao Comércio, de 1994, gerado no âmbito da OMC. 
ou cuja opção política não faça valer as exceções previstas na ordem internacional sobre a proteção dos inventos.

Verificada a amplitude conceitual da saúde, fica óbvio que só é possível precisar o que está implicado na definição do estado de saúde de pessoas concretas, situadas, que vivam ou trabalhem em determinada comunidade. Apenas essas pessoas têm legitimidade para decidir o ponto de equilíbrio entre, por exemplo, a proteção contra as infecções respiratórias e a limitação da circulação de veículos. Assim como, é apenas a comunidade local que pode legitimamente decidir que seja gasta parte significativa do orçamento nacional para oferecer transporte e tratamento para doentes que não encontrem possibilidade terapêutica naquele local. Deve-se concluir, então, que é do próprio conceito contemporâneo de saúde que decorre a exigência de sua definição em nível local, com a necessária participação da comunidade envolvida.

Pode-se afirmar que a noção de direito sofreu, de certo modo, evolução semelhante à da saúde, pois já a partir do século dezenove, com a implementação do Estado do Bem-Estar Social, instaurou-se um direito essencialmente diferente daquele advogado pelos burgueses revolucionários: um direito público mais amplo, porém menos coator (direito dos serviços públicos); misturando o público e o privado; desigual (desprezando a igualdade formal em nome da igualdade material); comportando direitos subjetivos ao recebimento de prestações; e cuja eficácia deve ser avaliada (institucionaliza-se a avaliação da administração pública, que permite sua fiscalização pelos parlamentos). Com a generalização do intervencionismo do Estado, que se serviu do direito para orientar outros sistemas sociais (economia, educação, cultura etc.) à conformidade com o interesse geral e não às exigências do mercado, prevaleceu a idéia de regulamentar as políticas privadas, assinalando-lhes uma finalidade (época áurea do planejamento). O direito passou a ser, então, bastante detalhado (portarias e circulares destinadas ao público externo) e dirigido pela administração pública (as agências independentes, nos Estados Unidos, reúnem o poder legislativo e o executivo). Uma vez que ele se caracteriza como um direito de princípios diretores, exigindo que seus aplicadores realizem uma escolha entre os diversos interesses presentes no caso concreto, se pode afirmar que o planejamento introduziu no direito uma lógica diametralmente oposta àquela que caracterizava o direito moderno.

Com a generalização dos mecanismos de democracia direta, exigindo grande dose de concertação, passa-se a incluir os destinatários na formação e na aplicação das regras. O direito nesse período apresenta as seguintes características: pouca transparência (a negociação não se submete à publicidade do direito do Estado e seleciona as pessoas ou grupos que dela participam); marcada setorialização (regulamenta parcelas que interessam a determinados grupos em prejuízo do interesse de toda a sociedade); muita 
seletividade e desigualdade (privilegia os grupos sociais organizados e os que têm interesses de curto prazo); necessidade de uma disciplina para a elaboração e interpretação das normas (processos complexos de formação das normas: informação, audiências e consultas públicas, além da complexidade científica dos temas a serem legislados ou julgados) ${ }^{(10)}$. É a esse tipo de Estado que assenta bem o rótulo de regulador, pois ele deve "definir as regras do jogo e harmonizar os comportamentos dos agentes econômicos e sociais"(11), empregando, sobretudo, a persuasão e a informação, que orientam a auto-organização da sociedade.

É possível concluir, portanto, que tanto a noção de direito como a de saúde no Estado contemporâneo implicam a mais ampla compreensão do ambiente em que será realizado o direito à saúde. É preciso que o legislador, o administrador e o juiz possam orientar-se em meio a tantas variáveis sociais, econômicas e culturais que participam da definição do estado de saúde das pessoas. São normas jurídicas que deverão revelar o sentido exato de saúde albergado por determinada comunidade. Aplicar o direito à saúde no século vinte e um exige que se verifique em cada momento da deliberação e da execução da política sanitária a obediência à Constituição, tanto preservando o valor saúde nela conceituado quanto buscando ouvir o povo para definir as ações que concretamente garantirão a saúde naquela situação específica. Em suma, na sociedade contemporânea o direito à saúde exige tanto a participação do Parlamento, legítimo representante dos interesses envolvidos tanto no processo de produzir e consumir quanto de controlar os riscos sanitários, como a participação dos cidadãos na elaboração e na implementação das normas e ações destinadas à promoção, à proteção e à recuperação da saúde.

3.1. Essa pequena digressão dogmática era necessária para que se possa compreender a complexidade da construção normativa desencadeada no Brasil após a afirmação constitucional da saúde como um direito de todos e um dever do Estado. Partindo, então, da Constituição da República Federativa do Brasil promulgada em 1988 verifica-se que "cuidar da saúde" é tarefa que deve incumbir a todas as esferas de poder político da federação. Ela foi enumerada entre as competências comuns à União, aos Estados, ao Distrito Federal e aos Municípios (art. 23, II). Foi prevista, também, a competência legislativa concorrente sobre a proteção e defesa da saúde, limitandose a União, nesse caso, ao estabelecimento de normas gerais, cabendo aos Estados e aos Municípios suplementá-las (art. 24, XII c/c. art. 30, II). Deixando de lado a melhor técnica legislativa, afirmaram-se as atividades destinadas ao "atendimento à saúde da população" a competência do Município para "prestar, com a cooperação técnica e financeira da União e do Estado, ...

(10) Os traços do direito em cada uma das fases apresentadas baseia-se, em grande parte na obra de MORAND, C.-A. Le droit néo-moderne des politiques publiques. Paris: LGDJ 1999.

(11) Cf. CHEVALLIER, J. Institutions publiques. Paris: LGDJ, 1996. p. 158. 
(esses) ... serviços" (art. 30, VII). Enfim, a Constituição federal vigente não isentou qualquer esfera de poder político da obrigação de proteger, defender e cuidar da saúde. Assim, a saúde - "dever do Estado" (art. 196) - é responsabilidade da União, dos Estados, do Distrito Federal e dos Municípios.

Tratando especificamente da saúde, como parte da seguridade social (art. 194), a Constituição abraçou a concepção atual de saúde, que não se limita à ausência de doenças e outros agravos, exigindo a realização de políticas públicas que tenham como finalidade "a redução do risco de doença e de outros agravos" e o "acesso universal igualitário às ações para sua promoção, proteção e recuperação” (art. 196). Ela organizou, também, o sistema público de saúde, exigindo que todas as ações e os serviços de saúde integrem uma rede que tenha apenas uma direção em cada esfera de governo. A Constituição requer, igualmente, que essa rede, prestando um atendimento integral às necessidades de saúde, seja organizada considerando os diferentes níveis de complexidade das ações e dos serviços de saúde, hierarquicamente. E, sobretudo, em coerência com os requisitos do Estado Democrático de Direito, dispôs que todas as ações e serviços de saúde se realizem com a efetiva participação da comunidade (art. 198).

O sistema público da saúde - Sistema Único de Saúde (SUS) deve ser financiado pelo orçamento da seguridade social, e das respectivas esferas de governo (art. 198, $\S 1^{\circ}$ ). Considerando, entretanto, que transformar a saúde em direito universal requer um dispêndio orçamentário expressivo, houve intensa pressão popular para que fossem vinculadas determinadas receitas ao financiamento do SUS. Assim, em setembro de 2000, foi aprovada uma Emenda Constitucional definindo recursos mínimos a serem aplicados em ações e serviços públicos de saúde. Eles devem ser calculados com base em percentuais do produto da arrecadação de alguns impostos, para as esferas estadual e municipal, e na forma definida em lei complementar, para a União (art. 198, $\S 2^{\circ}$ ). Ainda hoje, não foi aprovada a referida lei complementar, tendo-se decidido, por acordo político tácito, manter os percentuais de $12 \%$ para os Estados e $15 \%$ para os Municípios e que a União destine anualmente $10 \%$ das receitas correntes brutas dos orçamentos Fiscal e da Seguridade Social, constantes do Ato das Disposições Constitucionais Transitórias, que se esgotou no exercício de 2004. Esses valores figuraram no Projeto de Lei Complementar n. 01/03 aprovado na Câmara Federal, que após tramitação no Senado, voltou à Câmara em 2008.

Reconhecendo que todas as ações e serviços de saúde, sejam eles prestados pelo Poder Público ou pela iniciativa privada, possuem "relevância pública"(12), os constituintes de 1988 quiseram deixar claro que as pessoas

(12) Ver o documento elaborado por expressivas figuras do meio jurídico externando seu entendimento da expressão em DALLARI, S. G, et al. O conceito constitucional de relevância pública. Brasília: Organização Panamericana de Saúde, 1992 (Série direito e saúde, n. 1). 
físicas e as jurídicas de direito privado têm liberdade para atuar na área da saúde. De fato, o relacionamento com o setor privado da economia nacional que atua na área da saúde foi, realmente, o ponto mais polêmico da organização constitucional do sistema sanitário da República. Uma prova contundente dessa disputa é a redação dos arts. 197 e 199 da Constituição Federal. A melhor técnica legislativa não deixa dúvida sobre a dispensabilidade do segundo desses artigos quando o primeiro afirma que “... a execução ... (das ações e serviços de saúde) ... deve ser feita diretamente (pelo Poder Público) ou através de terceiros e, também, por pessoa física ou jurídica de direito privado.". Ora, aqui está declarada a liberdade de atuação da iniciativa privada na execução das atividades sanitárias. Nenhuma outra razão, a não ser o desejo de reafirmar tal liberdade, pode justificar a redação do caput do art. 199: "A assistência à saúde é livre à iniciativa privada." Apenas a existência de um ambiente de conflito pode explicar o reforço da liberdade imediatamente antes de submeter os prestadores privados de serviços de saúde a um contrato de direito público ou convênio, quando desejarem participar do "sistema único de saúde" e de vedar a destinação de recursos públicos para auxílios e subvenções às instituições privadas com fins lucrativos (art. 199, $\S \S 1^{\circ}$ e $2^{\circ}$ ).

Ao tratar da saúde, a Constituição da República decidiu, também, que regular "as condições e os requisitos que facilitem a remoção de órgãos, tecidos e substâncias humanas para fins de transplante, pesquisa e tratamento, bem como a coleta, processamento e transfusão de sangue e seus derivados" se inclui no tema proteção, defesa e cuidado da saúde, sendo, portanto, da competência de todas as esferas de governo. Ela determinou, igualmente, o respeito pela dignidade da pessoa humana, vedando expressamente todo o tipo de comercialização do sangue humano e de seus derivados e de órgãos, tecidos e substâncias humanas para fins de transplantes (art. 199, § $4^{\circ}$ ).

Reconhecendo a "relevância pública" das ações e serviços de saúde, a Constituição estabeleceu a competência do Poder Público para regulamentá-los, fiscalizá-los e controlá-los (art. 197), enumerando, exemplificativamente, algumas das atribuições do Sistema Único de Saúde no art. 200. A garantia do direito à saúde do povo dos Estados-membros e dos Municípios supõe, também, a formalização dos sistemas sanitários estadual e municipal. As diretrizes desses sistemas, em obediência ao preceito nacional (art. 198), o obrigam a, no gozo do poder político implícito à descentralização, realizar o atendimento integral da saúde, priorizando as atividades preventivas, sem prejuízo dos serviços assistenciais, e a contar com a participação da comunidade em sua organização. Os sistemas sanitários subnacionais devem, do mesmo modo, ser financiados com recursos do orçamento da seguridade social, da União, do Estado e dos Municípios, além de outras fontes (art. 198). 
A enumeração constitucional de competências implica a responsabilidade de realizar essas tarefas. São encargos que os governos estão obrigados a assumir, seja qual for a atividade necessária para sua efetivação. A declaração da descentralização, com direção única em cada esfera de governo, contida na Constituição da República, reserva poder político para os Municípios em matéria de saúde ${ }^{(13)}$. Nenhuma ordem constitucional estadual pode, portanto, negar essa afirmação, o que implica a indispensável compatibilização do mandamento federal e o disposto pelos Estados. Não se pode, por outro lado, supor que a falta de referência expressa à capacidade normativa estadual em matéria de saúde possa significar a sua inexistência. A organização federativa e a inequívoca redação dos artigos que disciplinam o assunto para toda a República, não permitem qualquer conclusão diferente.

Promulgada a Constituição Federal, abriu-se o período de elaboração das Cartas estaduais, que coincidiu com o da discussão dos Anteprojetos da Lei Orgânica da Saúde. Um rápido exame dos textos constitucionais dos Estados-membros ${ }^{(14)}$ revela que os constituintes estaduais decidiram definir pormenorizadamente o relacionamento do Estado com o setor privado da economia. De fato, as situações regradas em minúcias revelam as dificuldades do cotidiano dos administradores sanitários, que conseguiram convencer seus constituintes da importância da disciplina constitucional da matéria. Um bom exemplo dessa afirmação é a Constituição do Estado do Rio de Janeiro, que ao reescrever as normas nacionais sobre a participação das instituições privadas no sistema de saúde (art. 291), submete a decisão sobre a contratação de serviços privados à prévia "audiência dos conselhos municipais de saúde, quando de abrangência municipal, e do conselho estadual de saúde, quando de abrangência estadual" e determina que sejam aplicadas as sanções previstas em lei aos "serviços de saúde de natureza privada, que descumpram as diretrizes do sistema único de saúde, ou os termos previstos nos contratos firmados com o Poder Público". Ela também reafirma a vedação de destinar "recursos públicos para auxílios ou subvenções às instituições privadas com fins lucrativos", que o mesmo texto constitucional já impedira explicitamente, impedindo que o Estado conceda subvenção ou qualquer outro benefício às entidades dedicadas a atividades hospitalares e sanitárias, "cujos atos constitutivos e estatutos não disponham expressamente ... (quanto aos) ... fins exclusivamente filantrópicos e não lucrativos, ou que, de forma direta ou indireta, renumerem seus instituidores, diretores, sócios ou mantenedores", vedação já prevista no mesmo texto constitucional (art. 77, § 9). Igualmente, a prudente determinação de o

(13) A atribuição constitucional da competência sanitária municipal encontra-se discutida em pormenores em DALLARI, S. G. Competência municipal em matéria de saúde. Revista de Direito Público, São Paulo v. 22 n. 92, p. 172-177, 1989.

(14) Uma análise pormenorizada da matéria sanitária nas Constituições dos Estados brasileiros pode ser encontrada em DALLARI, S. G. Os Estados brasileiros e o direito à saúde. São Paulo: Hucitec, 1995. 
Estado instituir mecanismos adequados para coibir a imperícia, a negligência, a imprudência e a omissão de socorro nos estabelecimentos hospitalares, "cominando penalidades severas para os culpados", do caput do art. 303, é seguida de um parágrafo único que já define as penas a serem aplicadas quando se tratar de estabelecimento privado. É, também, garantido aos Municípios e ao Estado o ressarcimento das despesas com o atendimento dos segurados de empresas privadas de prestação de assistência médica, de responsabilidade das empresas (art. 304). E, textualmente, se proíbe que um servidor público participe de qualquer modo da administração de empresas privadas fornecedoras de suas instituições ou "que delas dependam para controle ou credenciamento" (art. 77, XXIV). Como, também, se proíbe a compra de medicamentos e soros imunobiológicos produzidos pela rede privada, salvo na hipótese de incapacidade da rede pública, prioritariamente estadual, fornecê-lo (art. 300).

O Pacto Federal de 1988, além de afirmar a autonomia política dos Estados-membros, de enumerar alguns de seus bens e duas competências privativas e de sugerir uma forma para a organização de seus serviços públicos, repete a fórmula tradicional de lhes reservar os poderes remanescentes ou residuais (CF, arts. 25, 26 e 18, § $4^{\circ}$ ). Um exame percuciente revela que as matérias assim caracterizadas se resumem a competências administrativas e financeiras ${ }^{(15)}$. Assim, sem qualquer dúvida, a esfera de poder político que detém a maior parcela de responsabilidade pela execução das ações e serviços de saúde - conforme o disposto na Constituição de 1988 - é o Município. Com efeito, nem mesmo a instituição do Sistema Único de Saúde ou a distribuição comum a todas as esferas das funções de prevenção, defesa e cuidado sanitário, anulou a obrigação posta especialmente aos Municípios de - com a cooperação técnica e financeira da União e dos Estados prestar serviços de atendimento à saúde da população (CF, art. 30,VII).

A Constituição Federal declarou a autonomia municipal (CF, art. 18) e afirmou que o Município é competente para dispor, legal e materialmente, sobre os assuntos de interesse local. É oportuno, então, lembrar que durante um século, no Brasil, os Municípios tiveram assegurada sua autonomia em tudo quanto respeitasse ao "seu peculiar interesse" (expressão do art. 68, da Constituição de 1891). E as tentativas de conceituação desse interesse foram inúmeras. Apenas por volta de 1950 uma definição alcançou relativo respeito, sendo adotada por insignes constitucionalistas de diversas correntes de pensamento. Trata-se daquela que, após distinguir o privativo do peculiar conclui: "O entrelaçamento dos interesses dos Municípios com os dos Estados, e com os interesses da Nação, decorre da natureza mesma das coisas. O que os diferencia é a predominância, e não a exclusividade."(16) Foi

(15) Cf. ALMEIDA, F. D. M. A repartição de competências na Constituição brasileira de 1988. São Paulo: Atlas, 1991. p. 153-166.

(16) Cf. DÓRIA, Sampaio. A. Autonomia dos Municípios. Revista da Faculdade de Direito de São Paulo, São Paulo, v. 24, p. 419-432, 1928. 
o mesmo critério - da predominância do interesse - o principio norteador da repartição de competências na federação brasileira de 1988. Ora, é evidente que o mundo contemporâneo praticamente não apresenta problemas que tenham reflexos circunscritos ao nível local, podendo-se concluir que os assuntos de interesse local devem ser compreendidos como aqueles referentes ao peculiar interesse municipal que, dentro da melhor técnica legislativa, serão definidos estudando-se caso a caso qual o interesse predominante para a fixação da competência do Município.

A Carta de 1988 cuida ainda da saúde quando ao tratar do Ministério Público, instituição essencial à função jurisdicional do Estado, afirma que ele tem o dever de zelar pelo efetivo respeito dos Poderes Públicos e das ações e serviços de saúde aos direitos constitucionalmente assegurados, promovendo as medidas necessárias a sua garantia (CF, art. 129, II). Isso acontece, também, quando ela cuida da Defensoria Pública, igualmente uma instituição essencial à função jurisdicional do Estado, que tem o dever de orientar e defender juridicamente, em todos os graus, os necessitados (CF, art. 134). Essas duas instituições de natureza administrativa constituem uma forma privilegiada para garantir o direito à saúde na ausência de maior especialização, pois qualquer que seja a situação econômica do indivíduo ou do grupo organizado, existe a previsão formal de uma instituição que deverá agir para efetivar a garantia do direito à saúde, inclusive pelo Poder Judiciário.

3.2. Em decorrência dos dispositivos da Constituição da República que dão competência à União para elaborar normas gerais sobre proteção e defesa da saúde (art. 24, XII, parágrafo único); para regulamentar, fiscalizar e controlar as ações e serviços de saúde (art. 197); e para organizar um sistema único de saúde, descentralizado, com atendimento integral e com participação da comunidade, financiado com recursos do orçamento da seguridade social, da União, dos Estados, do Distrito Federal e dos Municípios, além de outras fontes (art. 198), foi aprovado no Congresso Nacional, em setembro de 1990, Projeto de Lei Orgânica da Saúde. Enviado para a sanção do Presidente da República, o projeto, com vários artigos vetados, transformou-se na Lei n. 8.080, de 19 de setembro de 1990. Os vetos apostos ao referido projeto de lei abrangiam os dispositivos que disciplinavam a participação da comunidade na gestão do sistema único de saúde e as transferências intergovernamentais de recursos financeiros na área da saúde. Em rara demonstração de efetiva participação do movimento popular em saúde, foi possível articularem-se pressões sobre o Poder Executivo e sobre o Congresso Nacional, que resultaram na promulgação, em 28 de dezembro de 1990, da Lei n. 8.142, que disciplinou a matéria que havia sido prejudicada pelos vetos apostos ao Projeto de Lei Orgânica da Saúde. Assim, no Brasil, tem-se uma situação esdrúxula no que respeita à legislação de organização do sistema sanitário, uma vez que a Lei Orgânica da Saúde, na realidade são duas: a Lei n. 8.080 e a Lei n. 8.142, ambas de 1990. 
A Lei Orgânica da Saúde (LOS) visa regular, "em todo o território nacional, as ações e serviços de saúde executados, isolada ou conjuntamente, em caráter permanente ou eventual, por pessoas naturais ou jurídicas de direito público ou privado" (Lei n. 8.080, art. 1ํ) e esclarece que o Sistema Único de Saúde (SUS), constituído, na dicção constitucional, pelas ações e serviços públicos de saúde, envolve "o conjunto de ações e serviços de saúde, prestados por órgãos e instituições públicas federais, estaduais e municipais, da administração direta e indireta e das fundações mantidas pelo Poder Público ... e ... a iniciativa privada ... em caráter complementar" (Lei n. 8.080, art. $4^{\circ}$ ).

Para facilitar a execução de algumas das atribuições do SUS previstas no art. 200 da Constituição - como o controle e fiscalização de procedimentos, produtos e substâncias de interesse para a saúde, as ações de vigilância sanitária e epidemiológica e as de saúde do trabalhador e a participação na formulação da política e na execução das ações de saneamento básico (CF art. 200, I, II, IV) - a LOS define o conjunto de ações capaz de eliminar, diminuir ou prevenir riscos à saúde e de intervir nos problemas sanitários decorrentes do meio ambiente, da produção e circulação de bens e da prestação de serviços de saúde, como vigilância sanitária; o conjunto de ações que proporcionam o conhecimento, a detecção ou a prevenção de qualquer mudança nos fatores determinantes e condicionantes de saúde individual ou coletiva, com a finalidade de recomendar e adotar as medidas de prevenção e controle das doenças ou agravos, como vigilância epidemiológica; e o conjunto das ações destinado a promover e proteger a saúde dos trabalhadores, bem como a sua recuperação e reabilitação, como saúde do trabalhador (Lei n. 8.080, art. $6^{\circ}, \S \S 1^{\circ}, 2^{\circ}, 3^{\circ}$ ). Mantendo-se, ainda, o mesmo exemplo, a LOS esclarece, considerando as diretrizes constitucionais para a organização do SUS, a necessidade da integração, em nível executivo, das ações de saúde, meio ambiente e saneamento básico (Lei n. 8.080, art. 7ํ, X). Assim, a União, os Estados, o Distrito Federal e os Municípios devem, em seu âmbito administrativo, definir as instâncias e mecanismos de controle, avaliação e fiscalização das ações e serviços de saúde; acompanhar, avaliar e divulgar o nível de saúde da população e das condições ambientais; organizar e coordenar um sistema de informação em saúde; elaborar normas técnicas e estabelecer padrões de qualidade para promoção da saúde do trabalhador; elaborar normas técnico-científicas de promoção, proteção e recuperação da saúde; definir as instâncias e mecanismos de controle e fiscalização inerentes ao poder de polícia sanitária; fomentar, coordenar e executar programas e projetos estratégicos e de atendimento emergencial (Lei n. 8.080, art. 15, I, III, IV, XVI, XX, XXI). Mas, também, a União deve estabelecer normas e executar a vigilância sanitária de portos, aeroportos e fronteiras e executar as ações de vigilância sanitária e epidemiológica em circunstâncias especiais, como na ocorrência de agravos inusitados à saúde, que possam escapar do controle da direção estadual do SUS ou que representem risco de 
disseminação nacional (Lei n. 8.080, art. 16, VII e parágrafo único). E os Estados devem acompanhar, avaliar e divulgar os indicadores de morbidade e mortalidade e, suplementarmente, formular normas e estabelecer padrões de procedimentos de controle de qualidade para produtos e substâncias de consumo humano (Lei n. 8.080, art. 17, XIV, XII); assim como os Municípios devem normatizar complementarmente as ações e serviços públicos de saúde no seu âmbito de atuação (Lei n. 8.080, art. 18, XII).

Constitucionalmente, o sistema de saúde brasileiro não é juridicamente hierarquizado no que concerne à competência das diversas esferas de governo, mas o é enquanto sua organização prevê uma rede hierarquizada no que respeita à complexidade dos serviços postos à disposição da população. A base local do sistema, formada por parte de uma região municipal, um Município ou um consórcio de Municípios, deve proporcionar atendimento integral e contínuo, com a contribuição técnica e financeira dos Estados e da União. Para operacionalizar o mandamento constitucional, a LOS estabelece a responsabilidade dos Estados em relação aos estabelecimentos hospitalares de referência e à gestão dos sistemas públicos de alta complexidade, de referência estadual e regional (Lei n. 8.080, art. 17, IX) e a competência da direção nacional do SUS para definir e coordenar o sistema de redes integradas de assistência de alta complexidade (Lei n. 8.080, art. 16, III, a). No que respeita à cobertura do sistema de assistência à saúde, a LOS define como princípios inafastáveis em sua organização, a universalidade de acesso aos serviços de saúde e a capacidade de resolução desses serviços em todos os níveis de assistência; e a igualdade da assistência à saúde, sem preconceitos ou privilégios de qualquer hipótese (Lei n. 8.080, art. 7º I, XII, IV).

O sistema brasileiro de seguridade social se destina a assegurar os direitos relativos à saúde, à previdência e à assistência social e deve ser financiado por toda a sociedade mediante recursos provenientes dos orçamentos da União, dos Estados, do Distrito Federal e dos Municípios e das contribuições dos empregadores - incidente sobre a folha de salários, o faturamento e o lucro - e dos empregados, conforme mandamento constitucional (CF, arts. 194 e 195). A LOS estabeleceu que os recursos financeiros do SUS sejam depositados em conta especial, em cada esfera de sua atuação, e movimentados sob fiscalização dos respectivos Conselhos de Saúde (Lei n. 8.080, art. 33); e que os recursos do Fundo Nacional de Saúde sejam alocados, inclusive, como cobertura das ações e serviços de saúde a serem implementados pelos Municípios, Estados e Distrito Federal (Lei n. 8.142, art. 2ㅇ, IV). Esses recursos assim alocados deverão ser repassados de forma regular e automática para os Municípios, Estados e Distrito Federal, de acordo com os seguintes critérios: perfil demográfico da região, perfil epidemiológico da população a ser coberta, características quantitativas e qualitativas da rede de saúde na área, desempenho técnico, econômico e financeiro no período anterior, níveis de participação do setor saúde nos orçamentos estaduais e municipais, previsão do plano qüinqüenal de investimentos na rede, 
ressarcimento do atendimento a serviços prestados para outras esferas de governo; sendo que a metade dos recursos destinados a Estados e Municípios deverá ser distribuída segundo o quociente de sua divisão pelo número de habitantes, independentemente de qualquer procedimento prévio (Lei $\mathrm{n}$. 8.142, art. 3o c/c. Lei n. 8.080, art. 35).

As agências reguladoras, no Brasil, foram criadas como autarquias especiais, o que tem significado que - na legislação que as institui - são garantidos os mecanismos de afirmação de sua autonomia em relação à Administração direta. Também, como verdadeiras autarquias, o poder de

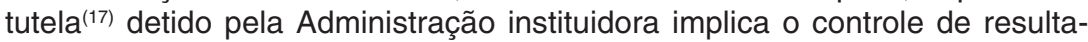
dos, que - nas chamadas agências reguladoras - é mediado pelo "contrato de gestão".

A lei federal n. 9.961, de 38 de janeiro de 2.000, criou a Agência Nacional de Saúde Suplementar, vinculada ao Ministério da Saúde, para regular, normatizar, controlar e fiscalizar as atividades que garantam a assistência suplementar à saúde (art. 1ํ). São suas atribuições: propor políticas e estabelecer as normas, os critérios, os parâmetros, o rol de procedimentos que as integram (art. 4ำ I - V e VII); autorizar o registro das operadoras e dos planos privados de assistência à saúde, seus reajustes e revisões e promover sua liquidação (art. 4, XVI, XVII, XX, XXXIII - XXXV); definir os critérios que lhe permitam exigir o cumprimento da Lei $n$. 9.656/98, que dispõe sobre os planos e seguros privados de assistência à saúde (art. 4º, IX - XVI, XXIX e XXX); monitorar, fiscalizar, controlar e avaliar as atividades das operadoras de planos privados da assistência à saúde (art. 4ํㅜ XXI - XXVIII); se autoorganizar (art. 4으, VIII e XXXVIII); promover a defesa do consumidor (art. 4으, XXXII e XXXVI); e zelar pela qualidade dos serviços de assistência à saúde (art. 4ำ $\mathrm{VI}$ ); e promover o ressarcimento ao SUS (art. $4^{\circ}, \mathrm{XXXVII).}$

A Agência Nacional de Saúde Suplementar, criada como autarquia especial, teve sua autonomia caracterizada pela independência administrativa, estabilidade de seus dirigentes e autonomia financeira. Seu contrato de gestão, instrumento para a avaliação da atuação administrativa da autarquia, deve ser negociado pelo seu Diretor Presidente e o Ministro de Estado da Saúde e aprovado pelo Conselho de Saúde Suplementar, órgão criado com a modificação da Lei Federal n. 9.656/98, que dispôs sobre os planos e seguros privados de assistência à saúde, introduzida com a Medida Provisória n. 1.976-25, de 6 de abril de 2000 (art. 35-A). Sua autonomia financeira é garantida, especialmente, pela constituição da receita com base no produto resultante da arrecadação da taxa de saúde suplementar; na retribuição por

(17) É o poder de influir sobre as autarquias, circunscrito aos atos previstos em lei e às hipóteses nela prefiguradas. No ensinamento de Celso Antônio Bandeira de Mello, entre outros, o contrato de gestão seria instrumento tanto do controle preventivo quanto do controle a posteriori (in MELLO, Celso antonio Bandeira de. Prestação de serviços públicos e administração indireta. São Paulo: Revista dos Tribunais, 1975). 
serviços de qualquer natureza prestados a terceiros; no produto da arrecadação das receitas das multas resultantes das ações fiscalizadoras; além de outras fontes (Lei Federal n. 9.961/00, art. 17).

Curiosamente, tanto na Lei Orgânica da Saúde como na Constituição Federal, as atividades destinadas à proteção da saúde são bastante enfatizadas, aparecendo tanto subsumidas na expressão vigilância sanitária, quanto expressas nas ações de controle e fiscalização de procedimentos, produtos e substâncias de interesse para a saúde, de participação na produção de medicamentos, equipamentos, imunobiológicos, hemoderivados e outros insumos sanitários, entre outras (CF art. 200 e Lei Federal n. 8.080/90, art. 6으, $\S 1^{\circ}$ ). A edição da Lei Federal n. 9.782/99, definindo o Sistema Nacional de Vigilância Sanitária (SNVS) dá, portanto, conseqüência lógica aos mandamentos constitucionais e legais que organizam o sistema de saúde no Brasil. É necessário observar que, enquanto organiza o Sistema Nacional de Vigilância Sanitária, essa lei tem característica de lei nacional. A lei reservou, assim, para a esfera federal a definição da política e do sistema nacional de vigilância sanitária, as atividades de normatização, controle e fiscalização de produtos, substâncias e serviços de interesse para a saúde e de vigilância sanitária de portos, aeroportos e fronteiras e todas as atividades executivas em situações especiais de risco à saúde. E para o conjunto federativo a manutenção do sistema de vigilância sanitária propriamente dito e de um sistema de informações em vigilância sanitária (Lei Federal n. 9.782/99, art. $\left.2^{\circ}\right)$.

Essa mesma lei criou, para a execução das atividades de competência da esfera federal, a Agência Nacional de Vigilância Sanitária (ANVISA) admitindo a possibilidade de realização de convênios com as esferas estadual e municipal para a realização das atividades conjuntas, previstas no sistema. A finalidade institucional da Agência Nacional de Vigilância Sanitária, criada como autarquia especial, é "promover a proteção da saúde da população", realizando para isso as atividades de "controle sanitário da produção e da comercialização de produtos e serviços submetidos à vigilância sanitária, inclusive dos ambientes, dos processos, dos insumos e das tecnologias a eles relacionados," e de "controle de portos, aeroportos e fronteiras". Seu contrato de gestão deve ser negociado pelo seu Diretor Presidente e o Ministro de Estado da Saúde. Ela tem assegurada independência administrativa, estabilidade de seus dirigentes e autonomia financeira (Lei Federal n. 9.782/99, arts. 3으, 6을 19 e 22).

É imperioso notar que a autonomia concedida à Agência Nacional de Vigilância Sanitária - pela lei de sua criação e disciplinada no seu regulamento (Decreto Federal n. 3.029/99) e em seus respectivos contratos de gestão - não a exime da obrigação de respeitar as diretrizes estabelecidas para todo o sistema público de saúde. Assim, por exemplo, sempre que realizar atividades em conjunto com as esferas estadual ou municipal, a Agência 
Nacional de Vigilância Sanitária deverá submeter-se à direção do sistema naquela esfera de governo; e devem ser permanentemente asseguradas as condições para o exercício da participação da comunidade na formulação de estratégias e no controle da execução da política de vigilância sanitária.

O exame do elenco de atividades de competência da Agência Nacional de Vigilância Sanitária, expresso nos arts. $7^{\circ}$ e $8^{\circ}$ de sua lei de criação, com as modificações que Ihe foram introduzidas pela Medida Provisória $n$. 2.190-34, de 23 de agosto de 2001, revela quatro tipos de atribuições. O primeiro refere-se à elaboração da política e à coordenação do sistema de vigilância sanitária (art. 7을 I a III, XVII a XXI, XXVII e $\S \S 1^{\circ}$ e $2^{\circ}$ e $4^{\circ}$ a $6^{\circ}$ ); em seguida encontram-se aquelas atribuições relacionadas, mais diretamente, à normatização e ao controle da qualidade dos produtos e dos serviços de interesse para a saúde (art. 7으, IV, VII a XVI, XXII e XXIV e $\S 3^{\circ}$ ); depois aquelas ligadas ao funcionamento da autarquia (art. 7으, VI e XXIII); e, finalmente, aquele tipo que engloba o conjunto das atribuições relativas à possibilidade de acesso a tais produtos e serviços de interesse para a saúde (art.

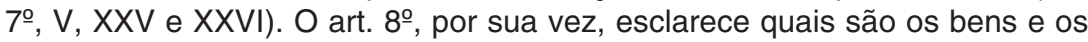
serviços submetidos à normatização e ao controle sanitário.

Note-se, novamente, que todo esse elenco de atividades deve-se conformar às exigências da Constituição e da LOS, devendo, portanto, estar orientado para a promoção da proteção da saúde, controlando os bens e a prestação dos serviços de interesse para a saúde - em todas as suas etapas e processos, incluindo o consumo - a fim de eliminar, diminuir ou prevenir riscos à saúde.

3.3. A operacionalização do federalismo de cooperação no campo da saúde gerou os mecanismos da responsabilidade solidária da União, dos Estados e dos Municípios para "cuidar" da saúde. As relações internas entre essas três esferas autônomas são regidas pelas Normas Operacionais Básicas (NOB) desde 1991. Essas normas operacionais são tornadas públicas por uma Portaria assinada pelo Ministro de Estado da Saúde. Elas têm, portanto, sua constitucionalidade derivada da estrita observância ao mandamento da Constituição da República, que afirma ser o "cuidado" da saúde competência comum das três esferas de governo. A primeira dessas normas (NOB 1/91) se limitava a aplicar o sistema de pagamento por produção de serviço ao setor público e a seguinte (NOB 1/92) vinculava a liberação de recursos à existência de um plano qüinqüenal.

Foi a terceira Norma Operacional Básica (NOB 1/93) que criou os mecanismos de gestão participativos e descentralizados. Ela criou as comissões entre gestores bi (gestores municipais e do Estado-membro) e tripartite (gestores dos Estados, dos Municípios e representantes do governo federal), encarregados de elaborar propostas para o sistema, acompanhar a implementação de normas e programas, avaliar os resultados e definir os critérios para a destinação de recursos. Ela criou, também, o mecanismo para a trans- 
ferência direta dos recursos federais para os Municípios (fundo a fundo) e os modelos de autonomia progressiva, de adesão voluntária. Assim, se, por exemplo, um Município decide aderir à forma mais autônoma, esse Município tem a liberdade de decidir sobre a aplicação de certa quantidade de recursos transferidos em função do tamanho de sua população. Uma avaliação desses mecanismos de descentralização e democratização oriundos da ordem constitucional instaurada em 1988 mostrou que a forma engenhosa de repartir rendas e distribuir responsabilidades, adotada no seio dessas comissões entre gestores, respeita verdadeiramente a autonomia federativa ${ }^{(18)}$.

A evolução das Normas Operacionais Básicas prosseguiu com a edição da NOB 1/96, que criou uma rubrica - PAB (Piso de Atenção Básica) especialmente para a atenção de base, além do sistema de pagamento por produção de serviço, e consagrou uma parte variável desse teto (PAB) aos programas federais (saúde da família, vigilância sanitária, assistência farmacêutica etc.) Assim, essa Norma Operacional Básica de 1996 limitou, em certa medida, a autonomia dos Estados e dos Municípios que, para receber mais recursos federais, devem adotar os programas federais. Em 2001, foi editada a Norma Operacional de Assistência à Saúde (NOAS 1/01) — publicada como Portaria Ministerial - que deixou aos gestores dos Estados a possibilidade de criar regiões de saúde e de estimular a criação de consórcios entre os Municípios. Observe-se que essa norma, fruto da colaboração do Conselho Nacional de Secretários Estaduais de Saúde (CONASS), do ConseIho Nacional de Secretários Municipais de Saúde (CONASEMS) e do governo, foi aprovada na Comissão Intergestora Tripartite (CIT) e no Conselho Nacional de Saúde.

Finalmente, em 2006, foi publicado, também em Portaria Ministerial, o Pacto pela Saúde, que contém, em realidade, três outros pactos. O pacto pela vida tem como prioridades a atenção à saúde das pessoas idosas; o controle dos cânceres de mama e de colo de útero, da mortalidade maternal e infantil e das doenças epidêmicas; a promoção da saúde; e a atenção básica. O pacto em defesa do SUS quer conseguir a regulamentação da Emenda Constitucional n. 29, que dispõe sobre o financiamento do Sistema Único de Saúde, e aprovar o orçamento consolidado do SUS (União, Estados e Municípios). E o pacto de gestão busca definir de maneira inequívoca a responsabilidade sanitária de cada instância de gestão do SUS; estabelecer as diretrizes de gestão para a descentralização, a regionalização, o financiamento, a programação pactuada e integrada, a regulação, a participação e o controle social, o planejamento, a gestão do trabalho e a educação em saúde. Esse Pacto pela Saúde deve incrementar o processo de busca de acordo entre as esferas estaduais e municipais.

(18) NASCIMENTO, P. R.; ZIONI, F. Relações federativas no SUS: autonomia nas relações intergovernamentais da CIB-SP. Revista de Direito Sanitário, São Paulo, ano 3, n. 2, p. 11-33, jul. 2002. 
Tanto a LOS quanto os instrumentos de gestão acima definidos prevêem a formulação de políticas e de planos municipais, estaduais e federais, de saúde ou de medicamentos e de sangue (Lei Federal n. 8.080, art. 6으, VI e $\mathrm{XI}$ ), podendo-se concluir que as políticas e os planos integram o cerne da política de Estado para a saúde pública. Além disso, assumindo-se a definição de políticas públicas como "programas de ação governamental visando a coordenar os meios à disposição do Estado e as atividades privadas para a realização de objetivos socialmente relevantes e politicamente determinados"(19), não há dúvida de que o Sistema Único de Saúde configura uma política pública de saúde, que tem sua primeira formulação na própria Constituição.

O rápido panorama da legislação sanitária brasileira, acima exposto, revela a vasta malha de atos normativos, legais e administrativos, que objetivam dar conseqüência aos princípios constitucionais. Tal normatização perfeitamente de acordo com os requisitos constitucionais - pode, entretanto, ser mudada com relativa facilidade. A maior resistência possível de ser encontrada é representada pela legislação ordinária, mesmo não exigindo quorum qualificado para modificações. Poder-se-ia, por exemplo, imaginar fórmula diferente das Comissões Intergestoras (CIBs ou CIT) ou das Normas Operacionais Básicas ou de Assistência à Saúde (NOBs ou NOASs), para organizar a distribuição da responsabilidade das três esferas da federação pelos cuidados da saúde, princípio constitucional da política sanitária brasileira. Não se poderia, entretanto, eliminar a obrigação de cooperação entre essas esferas ou de participação da comunidade na organização do Sistema Único de Saúde. Assim, é forçoso concluir que durante os últimos anos do século vinte se conformou - no exercício pleno das exigências do Estado Democrático de Direito - uma política pública de saúde que requer, por exemplo, que os Municípios assumam as atividades estabelecidas na forma de gestão contratada conforme a NOAS, existindo em atuação regular um Conselho de Saúde.

Por outro lado, o processo de planejamento e, portanto, a elaboração de planos de saúde, é uma exigência da Lei Orgânica da Saúde (Lei n. 8.080/ 90; art. 36). Esta determina que ele seja ascendente, ou seja, do nível local até o federal, a fim de que se compatibilizem as necessidades da política de saúde com a disponibilidade de recursos, nos planos de saúde dos Municípios, Estados, Distrito Federal e União. Especificamente com relação ao planejamento, a NOAS-SUS 01/02 contém algumas regras sobre o Plano Diretor de Regionalização (PDR). Ele é definido como um instrumento de organização do processo de regionalização da assistência em cada Estado e no Distrito Federal, devendo considerar a definição de prioridades de intervenção de forma coerente com a necessidade da população. E entre as definições trazidas pelo "Pacto de Gestão" (parte do Pacto pela Saúde de 2006), figuram o planejamento e a programação pactuada e integrada. O

(19) Cf. BUCCI, M. P. D. Direito administrativo e políticas públicas. São Paulo: Saraiva, 2002. p. 241. 
planejamento é definido como "estruturação de um sistema articulado e integrado entre as três esferas de gestão, baseado nas responsabilidades de cada uma delas, definindo-se objetivos e metas a serem atingidos. O sistema compreende, ainda, o monitoramento e a avaliação dos resultados das ações, por meio da pactuação tripartite das bases funcionais. Visa, também, a promoção da participação social e a integração intra e intersetorial (sic)". A Programação Pactuada e Integrada é compreendida como o "processo que visa definir o planejamento de ações de saúde em cada território, norteando a alocação dos recursos financeiros para a saúde, a partir de critérios e parâmetros pactuados entre os gestores" (item III).

A simples apresentação da construção normativa revela a complexidade do direito à saúde no Brasil. Ela revela, acima de tudo, que vem sendo dado um tratamento absolutamente consentâneo às exigências doutrinárias e práticas postas pelas noções de direito e saúde no século vinte e um. Com efeito, em cada momento de deliberação da política sanitária brasileira se tem buscado preservar o valor saúde abrigado na Constituição ao mesmo tempo em que se procura ouvir o povo organizado nos Conselhos e Conferências de Saúde. Enfim, o arcabouço normativo construído em torno do direito à saúde permite aos operadores do direito realizar o direito à saúde, inclusive quando ele depender da atuação do Poder Judiciário.

4. A construção do direito à saúde, com toda a abrangência que the foi dada no texto constitucional, exigindo para sua garantia o controle popular das políticas públicas, tem sido efetivada com muita lentidão pelo Poder Judiciário. Deve-se reconhecer, entretanto, que a dificuldade de compreender a amplitude do direito à saúde é devida tanto aos fatores culturais quanto, sobretudo, à inexperiência dos operadores do direito no tratamento jurídico das políticas públicas. Com efeito, a descoberta dos germes causadores de doença e o seu subseqüente isolamento, que possibilitou o desenvolvimento de remédios específicos, somada ao verdadeiro culto à ciência, predominante no século vinte, induziu a disseminação popular do conceito de saúde como ausência de doenças. As drogas aperfeiçoadas, adequadamente empregadas, resultavam na cura de várias doenças, salvando muitas vidas. Assim, apesar de a sociedade que sobreviveu às Grandes Guerras mundiais ter adotado um novo pacto social, reconhecendo a essencialidade do equilíbrio interno e do homem com o ambiente (bem-estar físico, mental e social) para a conceituação da saúde, recuperando a experiência anterior da humanidade ${ }^{(20)}$, ainda predomina na sociedade contemporânea a compreensão de que ter saúde é não estar doente. E as pessoas que trabalham com o direito, é claro, não estão imunes a essa influência cultural.

(20) A história do desenvolvimento do conceito de saúde pública foi, por nós, apresentada no capítulo "Políticas de Estado e políticas de governo: o caso da saúde pública", in BUCCI, M. P. D. (org.) Políticas públicas: reflexões sobre o conceito jurídico. São Paulo: Saraiva, 2006. p. 247-266. 
Por outro lado, fruto da mesma ideologia - o positivismo científico ainda predomina no meio jurídico a compreensão de que todo o direito está contido na lei e que, portanto, a lei é o direito. Isso ajuda a explicar a grande dificuldade que têm os operadores do direito para trabalhar com o controle judicial das políticas públicas, uma vez que elas - entre outras características - envolvem distintos "suportes" legais. Além disso, elas existem para realizar direitos sociais, cujo reconhecimento como "verdadeiros" direitos tem sido dificultado sob os argumentos de que "não há poder subjetivo de obrigar à sua realização ou porque pressupõem sempre prestações estatais". Ora, como ensina o ilustre constitucionalista português José Joaquim Gomes Canotilho, tais argumentos partem de questionamento dogmático que supõe "uma estrutura de direito subjetivo pretensamente válida para todos os direitos e ramos do direito"(21), o que ainda precisa ser provado.

Desse modo, a construção jurisprudencial do direito à saúde é, também, bastante errática. Exemplo que parece revelar o conflito entre o reconhecimento do direito individual à saúde e da saúde enquanto um direito social pode ser encontrado nos Acórdãos do Superior Tribunal de Justiça. Examinando um Agravo Regimental em Recurso Especial originado de ação ordinária com pedido de tutela antecipada ajuizada em face do Estado objetivando o fornecimento de alimento indicado para paciente com distúrbio e dificuldade na ingestão de alimentos, a primeira turma decidiu, acompanhando o Ministro Relator Luiz Fux, invocando o princípio da dignidade da pessoa humana, que deveria ser concedido o medicamento, para que fosse dada "efetividade (à) regra constitucional que consagra o direito à saúde"(22). E a mesma Primeira Turma - em Recurso Especial contra acórdão que negou tratamento médico no exterior, pois uma vez "definidas pela Administração as metas prioritárias na área de saúde pública, dentro do âmbito da discricionariedade de que dispõe e sem ofensa aos limites legais e constitucionais, não cabe ao Judiciário perquirir os critérios adotados, tampouco substituílos. Daí por que, na espécie, não padece de ilegalidade a Portaria n. 763, de 07.04.1994, editada pelo Ministério da Saúde, que proibiu o custeio de tratamento médico no exterior por conta do Estado" - decidiu, contrariando o mesmo Ministro Relator, considerar "legítima a Portaria n. 763/1994, do Ministério da Saúde, que vedou o financiamento de tratamento médico no exterior pelo SUS"(23), negando provimento ao recurso.

Do mesmo modo, o Supremo Tribunal Federal tem demonstrado a dificuldade de alcançar uma concepção coerente do Sistema Único de Saúde. De fato, o SUS é uma política pública bastante bem construída a partir do suporte constitucional e que alcança a precisão das metas tendo como suporte a Programação Pactuada e Integrada (PPI) aprovada pelas Comissões

(21) Cf. COUTINHO, N. M. Canotilho e a Constituição dirigente. Rio de Janeiro: Renovar, 2003. p. 36.

(22) Processo: AgRg no REsp n. 750738 / RS; Agravo Regimental no Recurso Especial n. 2005/0080582-3.

(23) Processo: AgRg no REsp n. 750738 / RS; Agravo Regimental no Recurso Especial n. 2005/0080582-3. 
Intergestoras, como já se verificou. Discutindo a competência das diversas esferas de poder político da federação em relação à distribuição de competências em matéria de saúde, entretanto, o STF tem revelado o mesmo comportamento errático. Em decisão de Agravo Regimental em Recurso Extraordinário a respeito do Programa de distribuição gratuita de medicamentos a pessoas carentes e a portadores do vírus HIV, disciplinado no Estado do Rio Grande do Sul por meio da Lei n. 9.908/93, o STF afirmou ser perfeitamente possível aos entes públicos pactuar acordos "no que concerne à reserva de atribuições para a operacionalização dos serviços de saúde", observando "critérios de conveniência e oportunidade da Administração para atender a demanda da população na área da saúde"(24).

Por outro lado, ainda quando diretamente provocado a examinar a construção dessa política pública, o Supremo Tribunal Federal foge do tema. É o caso, por exemplo, da decisão, em Agravo de Instrumento, tendo por base a construção constitucional, legal e administrativa que organizou a prestação de assistência especializada a integral aos portadores de câncer. Nela, o STF sequer examinou a pertinência dos atos normativos citados, afirmando a "obrigatoriedade de o Poder Público (União, Estados e Municípios) fornecer, gratuitamente, a pessoas carentes, portadoras de doenças graves, medicamentos destinados a assegurar condições do direito à continuidade da vida digna e a preservação da saúde". Assim, curiosamente, mesmo lembrando que o "direito de todos à saúde (é) "garantido mediante políticas sociais e econômicas que visem à redução do risco de doença e de outros agravos e ao acesso universal e igualitário às ações e serviços para sua promoção, proteção e recuperação'”', essa decisão não fez qualquer referência aos suportes legais da política pública em questão(25).

Comportamento semelhante ocorre no Superior Tribunal de Justiça. Em Recurso Especial onde se discutia a legitimidade passiva da União para responder à indenização decorrente de erro médico ocorrido em hospital da rede privada durante atendimento custeado pelo SUS, ele trouxe à baila o suporte legal organizador dessa política. Com efeito, a decisão reconhece a organização dos serviços para a promoção, proteção e recuperação da saúde efetuada pela Lei n. 8.080/90 e conclui — reafirmando jurisprudência anterior da mesma turma - que "Relativamente à execução e prestação direta dos serviços, a Lei atribuiu aos Municípios essa responsabilidade (art. 18, incisos I, IV e V, da Lei n. 8.080/90), compatibilizando o Sistema, no particular, com o estabelecido pela Constituição no seu art. 30, VII: 'Compete aos Municípios (...) prestar, com a cooperação técnica e financeira da União e do Estado, serviços de atendimento à saúde da população'(26)"(27). Esse mesmo

(24) RE-AgRg n. 259508/RS.

(25) Al n. 559055/RS.

(26) REsp n. 873.196/RS.

(27) Processo: REsp n. 717800/RS. 
tribunal examinou a questão da implementação do Modelo de Assistência à Saúde do Índio e a instalação material dos serviços de saúde à população indígena, apresentadas como claramente como uma política pública. Nesse julgado, discorreu largamente sobre a fundamentalidade material e formal do direito à saúde; o princípio da máxima efetividade da Constituição; e a cláusula da reserva do possível e terminou por dar razão à parte que buscava a implementação da política já esboçada no Decreto n. 1.141, de 19 de maio de 1994. Nenhuma palavra, entretanto, foi dita a respeito da política em questão e nem o seu suporte legal foi sequer mencionado(28).

No que respeita ao controle dos recursos financeiros destinados ao sistema de saúde, entretanto, pode-se identificar certa predominância de decisões judiciais dos tribunais superiores assegurando a possibilidade de seu exercício. Assim, seguidamente o Supremo Tribunal Federal tem reconhecido a legitimidade ativa do Ministério Público Federal para propor ação civil pública tendo por objeto a anulação de contrato para prestação de serviços do Sistema Único de Saúde (SUS), uma vez que se impõe "a tutela do patrimônio público, sendo vedada a contratação de rede hospitalar privada, no âmbito do SUS, sem o devido procedimento licitatório"(29). Em outro Recurso Especial, o interesse da União na lide foi reforçado com o argumento de que além de "cuidar-se de repasses de recursos financeiros da Fazenda Federal para o Estado, realçou-se que da infração às disposições da legislação pertinente decorria também prejuízo aos serviços federais, pois a esses incumbe não só a distribuição dos recursos, mas ainda a supervisão de sua regular aplicação, inclusive com auditorias no plano dos Estados"(30). Também, decidindo uma Reclamação, o STF prestigiou o Verbete n. 208 da Súmula do Superior Tribunal de Justiça, que assevera "que o fato de o Termo de Parceria indicar como fonte de custeio os recursos provenientes dos royalties e do fundo especial de participação apenas torna obscura a destinação dada aos recursos federais que aportam aos cofres municipais, cuja prestação de contas se dá perante órgão federal de fiscalização"(31).

A construção jurisprudencial do direito à saúde, quando relacionada às atividades cominadas às agências reguladoras da área: ANS e ANVISA, tem, por outro lado, seguido um mesmo caminho de reforço de suas competências normativas, especialmente no Superior Tribunal de Justiça. Assim, em Recurso Especial que cuidava de cláusula de exclusividade exigindo a fidelidade do médico à cooperativa do plano de saúde, o STJ afirmou que "o direito pleiteado pela recorrente compromete, por via obliqua, os direitos à saúde (CF. art. 196), na medida em que a exclusividade cerceia o acesso àqueles médicos profissionais vinculados à cooperativa ${ }^{(32)}$. Do mesmo modo,

(28) Processo: REsp n. 811608/RS.

(29) RE n. 284712/MA.

(30) RE n. 371888/PB.

(31) Rcl n. 5456/RJ.

(32) Processo: REsp n. 768118/SC. 
decidindo um Agravo Regimental na Suspensão de Liminar e de Sentença, concluiu estar caracterizada a lesão à saúde e à ordem pública administrativa, "com a interferência na legítima atividade regulatória desempenhada pela ANS, respaldada em discricionariedade técnica"(33).

Em matéria de vigilância sanitária, o Superior Tribunal de Justiça tem compreendido, por exemplo, ser legal a atuação da Divisão de Vigilância Sanitária, fiscalizando, notificando e proibindo que as farmácias, drogarias, drugstores e estabelecimentos comerciais congêneres procedam ao recebimento das contas de água, luz, telefone, condomínio, plano de saúde e similares, uma vez que "o art. 55, da Lei 5.991/73 veda a utilização da farmácia ou drogaria para outro fim diverso do licenciamento"(34) ou que a "licença para funcionamento de farmácia ou drogaria constitui ato de natureza vinculada, de modo que é vedada a utilização das dependências desses estabelecimentos para fim diverso do previsto no licenciamento (Lei 5.991/73, arts. 21 e 55). Portanto, não há plausibilidade jurídica na utilização desses estabelecimentos para vender alimentos ou utilitários domésticos"(35). No mesmo tema, examinando um Recurso Ordinário em Mandado de Segurança, o STJ decidiu que "é lícito ao Prefeito baixar decreto, proibindo, nas cantinas das escolas municipais, a venda de alimentos excessivamente calóricos. Tal decreto - que não é regulamentar, mas regimental — não interfere com as normas gerais de vigilância alimentar"(36). E, em Recurso Especial, afirmou que a alegação de ser o produto registrado "com validade por prazo indeterminado, não necessitando de renovação, não tem prevalência sobre o dever de controle e proteção à saúde e ao meio ambiente pelo poder público". E insistiu que a concessão de registro anterior, "não impede que a autoridade administrativa, diante da possibilidade de os fertilizantes, depois de ingressarem no mercado, revelarem-se potencialmente nocivos à saúde ou ao meio ambiente, exija, por meio de ato administrativo (norma infralegal), o cumprimento de novos requisitos"(37). Ainda tratando da vigilância sanitária, o Superior Tribunal de Justiça vem reafirmando a validade da Portaria n. 344, da Secretaria de Vigilância Sanitária do Ministério da Saúde, que classifica determinadas substâncias como psicotrópicos anorexígenos, fazendo incidir, então, as sanções previstas na Lei n. 6.368/76(38).

Tratando da proteção da saúde do trabalhador, pode-se notar, igualmente, certa consistência nas decisões do Superior Tribunal de Justiça, reconhecendo, por exemplo, em pedido de habeas corpus, que o crime de perigo para a vida ou saúde de outrem é de perigo concreto, não sendo

(33) Processo: AgRg na SLS n. 163/PE.

(34) Processo: REsp n. 772972/SE.

(35) Processo: AgRg no REsp n. 747063/SC.

(36) Processo: RMS n. 16694/RJ.

(37) Processo: REsp n. 960017/PR.

(38) Habeas Corpus n. 2005/0042941-0. 
"necessário esperar que suceda início de acidente grave, para só, aí, ter como caracterizado o ilícito do art. 132, do CP". O habeas corpus foi, então, indeferido, reconhecendo-se a responsabilidade criminal do acusado "por não ter adotado as providências de segurança, plenas condições de defesa, pelo exato conhecimento da natureza das acusações que lhe são feitas, por manter-se omisso, segundo a denúncia, expondo os empregados da empresa a perigo a saúde e a vida"(39). Em outra decisão, em Recurso Especial cuidando do fornecimento e uso obrigatórios dos equipamentos de proteção individual (EPI), deduziu-se a responsabilidade do empregador por controlar o uso de tais equipamentos, com base tanto na lei fruto da atividade dos Parlamentos (art. 19, § 1으, da Lei n. 8.213/91 e arts. 157, 158, 200 e 632, da CLT) quanto na norma regulamentar (NR-6). De fato, com base no voto do Ministro Relator Herman Benjamin, a decisão afirmou que "No campo da segurança do trabalho, por força da sistemática do Estado Social, ao empregador impõe-se a obrigação primária de zelar, de forma ativa e insistente, pela saúde e segurança do trabalhador" e que "No que se refere às exigências de EPI, o empregador, para dizer-se em plena sintonia com o espírito e conteúdo do ordenamento jurídico de tutela do trabalhador exposto a riscos, precisa cumprir, de maneira cumulativa e simultânea, as obrigações de dar, orientar, fiscalizar, punir e comunicar"(40).

No que se refere aos reflexos sobre a saúde das medidas de proteção ao meio ambiente volta-se, contudo, a identificar o mesmo comportamento errático dos tribunais superiores. Assim, valorizando os princípios e realizando uma ponderação entre as exigências para preservação da saúde e do meio ambiente e o livre exercício da atividade econômica (art. 170 da Constituição Federal), o Superior Tribunal de Justiça entendeu que "a coleta de lixo constitui serviço essencial, imprescindível à manutenção da saúde pública, o que o torna submisso à regra da continuidade. Sua interrupção, ou ainda, a sua prestação de forma descontinuada, extrapola os limites da legalidade e afronta a cláusula pétrea de respeito à dignidade humana, porquanto o cidadão necessita utilizar-se desse serviço público, indispensável à sua vida em comunidade" e que "não há discricionariedade do administrador frente aos direitos consagrados, quiçá constitucionalmente. Nesse campo, a atividade é vinculada sem admissão de qualquer exegese que vise afastar a garantia pétrea"(41). No mesmo sentido, reconheceu o Supremo Tribunal Federal, em Ação Direta de Inconstitucionalidade, haver "Constitucionalidade formal e material do conjunto de normas (ambientais e de comércio exterior) que proíbem a importação de pneumáticos usados ${ }^{(42)}$, não provendo o Agravo Regimental em questão. Já em duas outras oportunidades o Supremo

(39) HC n. 80721/SP-SÃO PAULO.

(40) Processo: REsp n. 171927/SC.

(41) Processo: REsp n. 575998/MG.

(42) STA-AgRg n. 118/RJ-Rio de Janeiro. 
Tribunal Federal, também em matéria da repercussão sanitária da proteção ambiental, decidiu em Ação Direta de Inconstitucionalidade que a proteção e defesa da saúde por meio da rotulagem informativa de produtos transgênicos por norma estadual não eximem o legislador estadual da limitação da autorização constitucional "voltada para o preenchimento de lacunas acaso verificadas na legislação federal"(43). E que é "apenas de natureza supletiva (CF, art. 24, $\S \S 1^{\circ}$ e $4^{\circ}$ ) a competência estadual para editar normas gerais sobre a matéria", não havendo justificativa "para tratamento particular e diferenciado" de um Estado, permitindo que adote "Rotulagem com informações preventivas a respeito dos produtos que contenham amianto"(44).

Muitos dos elementos que configuram o conceito jurídico da saúde que ganhou foro constitucional em 1988 ainda não foram examinados pelos tribunais superiores. Outros são objeto de algumas raras decisões. É o caso dos recursos humanos em saúde, onde o Superior Tribunal de Justiça, ao reconhecer a legitimidade do Ministério Público Federal para a promoção de ação civil pública, visando a reintegração de agentes sanitários responsáveis por campanhas de prevenção e combate a epidemias e doenças endêmicas, afirmou que a demissão generalizada desses agentes "poderia gerar danos irreparáveis à saúde da coletividade"(45). Esse mesmo tribunal, examinando Embargos de Declaração em Recurso Especial, afirmou que "compete à União, pelo Ministério da Saúde, controlar e fiscalizar procedimentos no âmbito do SUS e promover articulação com órgãos educacionais e de fiscalização do exercício profissional, bem como com entidades representativas de formação de recursos humanos na área da saúde"(46). É o caso, também, do Supremo Tribunal Federal que, em Ação Direta de Inconstitucionalidade de lei que garantia a meia entrada aos doadores regulares de sangue, considerando que a "Constituição do Brasil em seu art. 199, § 4, veda todo tipo de comercialização de sangue, entretanto estabelece que a lei infraconstitucional disporá sobre as condições e requisitos que facilitem a coleta de sangue" e que o " ato normativo estadual não determina recompensa financeira à doação ou estimula a comercialização de sangue", concluiu que "Na composição entre o princípio da livre iniciativa e o direito à vida há de ser preservado o interesse da coletividade, interesse público primário", julgando a ação improcedente ${ }^{(47)}$.

O exame das decisões aqui realizado, que envolveu a totalidade das ementas com o termo saúde disponíveis nos endereços eletrônicos dos respectivos tribunais, não deixa qualquer dúvida de que o controle judicial da política pública de saúde ainda não foi instaurado no Brasil. Raras decisões

(43) ADI n. 3645/PR-Paraná.

(44) ADI n. 2656/SP-São Paulo.

(45) Processo: REsp n. 177883/PE.

(46) Processo: EDcl no REsp n. 693466/RS.

(47) ADI n. 3512/ES - Espírito Santo. 
das Cortes Superiores trabalham com o conceito e não foi possível encontrar qualquer decisão em que houvesse sido suscitada a exigência da participação popular para a caracterização do direito à saúde constitucionalmente assegurado. Esse é, certamente, um caminho longo, que apenas começa a ser trilhado.

Em suma, a afirmação constitucional do direito à saúde foi, no Brasil, uma experiência única. Absolutamente consentânea com a evolução do direito no final do século vinte, ela veio com as bases da política destinada a realizar esse direito e exigiu a participação popular para sua definição e implementação. Essa necessária participação do povo na realização do direito torna a política pública de saúde igualmente adequada aos requisitos postos pelo conceito contemporâneo de saúde, uma vez que ele implica ao mesmo tempo - aspectos de direito individual, de direito coletivo e também difuso, que só podem ser justamente equacionados com a participação direta do povo em sua definição.

É evidente, entretanto, que essa contemporaneidade do direito à saúde, tal qual construído na Constituição brasileira de 1988, traz consigo sérias dificuldades. É preciso que todos os atores envolvidos no processo de definição e implementação da política de saúde - indispensável à realização do direito à saúde - encontrem o sentido exato do termo saúde em cada realidade, ouvindo ou verificando se foi ouvida a comunidade nesse processo. Em grandes linhas se pode concluir que isso vem acontecendo, tendo tanto a normatização fruto da atividade dos Parlamentos, tanto aquela que se dá na Administração, procurado ouvir o povo organizado. E são muitos os atos normativos em vigor para a realização do direito à saúde no Brasil, muitos deles não editados por lei em sentido estrito. Isso talvez ajude a explicar a difícil implementação do controle judicial da política pública de saúde. Além disso, compreender, por exemplo, que a própria significação do termo saúde depende da participação do povo é algo novo também para os atores do mundo jurídico, formados na concepção de que a única estrutura válida para o direito subjetivo é aquela configurada na Modernidade.

Tem-se, portanto, um largo caminho a percorrer para que o direito à saúde afirmado em 1988 seja uma realidade para todos no Brasil. Deve-se, contudo, reconhecer que tal afirmação tem demonstrado um grande vigor jurídico, induzindo a implementação da política sanitária desenhada na Constituição, tanto por meio de leis quanto dos demais atos normativos, como, também, pelo ainda incipiente - mas crescente - controle judicial de sua realização.

\section{REFERÊNCIAS BIBLIOGRÁFICAS}

ALMEIDA, F. D. M. A repartição de competências na Constituição brasileira de 1988. São Paulo: Atlas, 1991. 
BUCCI, M. P. D. Direito administrativo e políticas públicas. São Paulo: Saraiva, 2002.

BUCCI, M. P. D. Políticas públicas: reflexões sobre o conceito jurídico. São Paulo: Saraiva, 2006.

CHEVALLIER, J. Institutions publiques. Paris: LGDJ, 1996.

COUTINHO, N. M. Canotilho e a Constituição Dirigente. Rio de Janeiro: Renovar, 2003.

DALLARI, S. G. O direito à saúde. Revista de Saúde Pública, São Paulo, v. 22, n.1, p. 57-63, 1988.

DALLARI, S. G. Competência municipal em matéria de saúde. Revista de Direito Público, São Paulo v. 22 n. 92, p. 172-177, 1989.

DALLARI, S. G, et al. O conceito constitucional de relevância pública. Brasília: Organização Panamericana de Saúde, 1992 (Série direito e saúde, n. 1).

DALLARI, S. G. Os Estados brasileiros e o direito à saúde. São Paulo: Hucitec, 1995.

DÓRIA, Sampaio. A. Autonomia dos Municípios. Revista da Faculdade de Direito de São Paulo, São Paulo, v. 24, p. 419-432, 1928.

MELLO, Celso antonio Bandeira de. Prestação de serviços públicos e administração indireta. São Paulo: Revista dos Tribunais, 1975

MORAND, C. A. Le droit néo-moderne des politiques publiques. Paris: LGDJ 1999.

NASCIMENTO, P. R.; ZIONI, F. Relações federativas no SUS: autonomia nas relações intergovernamentais da CIB-SP. Revista de Direito Sanitário, São Paulo, ano 3, n. 2, p. 11-33, jul. 2002.

RODRIGUES NETO, E. A via do parlamento In: FLEURY, S. (Orgs.) Saúde e democracia: a luta do CEDES. São Paulo: Lemos, 1997.

SILVA, José Afonso. Aplicabilidade das normas constitucionais. 3. ed. São Paulo: Revista dos Tribunais, 1998.

WHITACKER, F. et al. Cidadão constituinte: a saga das emendas populares. Rio de Janeiro: Paz e Terra, 1989. 